edge (100b). Can we explain an intuition in words? Not usually. Metaphor merely evokes the insight. And, as important as words are in shaping our thoughts and actions, words are not all we have. In science, there are photographs, diagrams, and handshakes, visual and nonverbal communication. But beyond that, there is silence. Barbara McClintock knew how to cultivate silence, and she developed a meditative awareness from which her scientific understanding arose. McClintock's was a relaxed and focused clarity, a penetrating insight into nature. The adepts who study the $I$ ching know something of this silence. They have an understanding of the I ching more subtle than that which is conveyed by language, even though many of them know Chinese and the nuances of the ideograms. To know the I ching is to experience the changing of the seasons, the shift of energy in the day. Once this experience is internalized, there is no longer any need for the symbol represented by the hexagram. The martial art of bagua helps the cultivation of this silent understanding, for the movements of bagua are based on the hexagrams of the $I$ ching. When the movements are internalized, so too is a subtle understanding of the $I$ ching.

Papin speaks of moving toward holism, toward unity. Then she says that we only have words and that, since our words are Indo-European, they are extremely limited, bound to fragment. Only if we let them. This is not a universe. This is a universe. This is and is not a universe. The words become a mantra moving toward an experience of unity-and this experience is often wordless. In t'ai chi ch'uan, the practice of "push hands" allows two people to become a métaphore vive. Each partner touches the other, and the two move in a circle. Two separate selves recognize their interconnection. The art of push hands is to merge completely, so that when one partner moves, the other anticipates the movement. Push hands can be practiced as a martial art, as an exercise for health, and as a metaphor for the expansion and contraction of the universe.

How can we move this way in argument, an engagement in which we believe that strength is in the assertion of a separate view, not in the movement toward an integral view? Burke, Schilb, Jarratt, and others have warned that we must not discard one viewpoint for another, that we must take care not to confuse unity with consensus. We might learn again from push hands, where both partners are integral to the movement. Each partner is intact as an individual but, at the same time, inseparable from the other. Is there a similar way to integrate multiple perspectives? Can we together choreograph a dynamic dance of diversity, where each perspective is a distinct and interdependent step toward a deeper awareness? There is much to explore here: the trace of insight that we find in metaphor, the merging of viewpoints that we find in the synthesis of dialectic. And beyond the words, we have silence.

\section{MARIANTHE KARANIKAS}

Southwest Missouri State University

\section{To the Editor:}

Although I was pleased to see in PMLA an essay on science and literature, Liliane Papin's "This Is Not a Universe: Metaphor, Language, and Representation" is disappointing because the author simply reproduces the familiar claims and limitations of a large vein of work in the area. Beginning with the usual condemnation of that undefined nemesis "positivist science," Papin goes on to amplify the antirealist notion that scientific language is metaphoric and is unable to convey knowledge of a mind-independent natural reality. This constructivist "finding" is said to have the happy result of closing the gap between the natural sciences and literature: Papin concludes with the idea that "we are all poets and the world is our metaphor" (1264).

Rhetorical demystifications of science's prestigious results may seem reassuring to some literary critics, but that does not make such arguments an effective or credible interdisciplinary strategy. Papin's theoretical canon is highly exclusionary, for she fails to mention any of the important recent work in epistemology and in the history and philosophy of science that does not echo her notions. I have in mind, for example, the carefully argued positions of such prominent figures as Ruth Garrett Millikan, Richard Boyd, Frederick Suppe, Susan Haack, Richard W. Miller, and W. H. Newton-Smith. Papin's article is a fine instance of what Fred Crews has recently called "duty-free interdisciplinarity," the tendency among literary critics to ignore the standards and results of the fields from which they borrow. This facile interdisciplinary strategy is especially unacceptable when it is a matter of reducing the complexities of extraordinary-and at times terrifying-discoveries in the natural sciences to a single error about the metaphoric nature of scientific (and all) language.

The shortcoming I have in mind is especially salient in Papin's remarks on AIDS-related research. Citing only one source on the topic - an article in Le point - Papin contends that AIDS research suffers from a 
basic epistemological problem, that of relying on Western science's emphasis on fragmentation and segmentation. Instead of looking for a "magic bullet" to cure the virus, we need a "global" research strategy that "links the syndrome to a background of general health" (1263-64). I find it irresponsible for a literary critic to pronounce on such a complex issue in this casual manner, and I am particularly concerned about the dangers of shifting the emphasis from properly political to epistemological matters. How does Papin know that the epistemic stance constitutive of the entire Western scientific paradigm - and not inadequate funding and organization-should figure highest on the list of problems requiring public debate and action? It could be that no cure for the viruses will be found, but that does not mean that it is a bad idea to engage in a systematic search for one using the most reliable available scientific methods. It is the holists and rhetoricians who are hoping for a properly magic solution to AIDS-namely, a global paradigm shift in health and epistemology.

Papin's ideas about language are as selective and underargued as are her pronouncements on science. It is embarrassing to see the author of a PMLA article trot out the "discoveries" of Benjamin Whorf at a time when linguists and philosophers of language have abandoned his wild claims and have offered instead an array of rigorous hypotheses and models. The literature on Whorf and Sapir presents many conceptual and empirical arguments against accepting the idea that different natural languages "construct" incommensurable "realities" for the communities of agents who speak the languages. One standard objection is that if this thesis were true, no one could know that it was since no single language could offer neutral access to the world of incommensurable and radically distinct systems of language-reality. Is Whorfian relativity, then, just the effect of a language? Which language is that? Papin's treatment of these and related issues is uninformed and superficial.

Papin mentions an essay of mine in which I develop some arguments against the kind of irrational and self-serving form of interdisciplinarity that she practices. Literary theorists and critics, I contend, often fail to observe a number of basic epistemic norms characteristic of serious research in both the human and the natural sciences. More specifically, I point to a case in which a derivative student essay was presented as having important consequences for literary knowledge. Yet Papin does not bother to engage these arguments. Instead, she advises a sort of comic relief: "[I]f one can put on hold the question of truth for a moment, [the] call for metaphorical play is also useful.
Even though the student's essay may have been prompted more by laziness than by deconstructive understanding, it does offer a metaphor for the poem and reflects enough knowledge of deconstruction to swing the pendulum to the extreme-which was a laugh" (1262). I want to point out that my concern in discussing the student's paper was not with the student's motives but, rather, with the error of the professors who reproduced it in a scholarly publication. What would literary knowledge have to be like, I query in the article, if there really were no difference between derivative replications of interpretive styles and genuine explanations and discoveries? Papin's answer is clear: literary knowledge would be a field where the question of truth is put on hold, not for a moment, but once and for all. Fortunately, the fact that metaphor and language play a role in all the sciences does not support the idea that basic epistemic values and criteria should be abandoned when the results of research are judged. It is my hope that in the future rigorous standards will be respected when editors and readers of $P M L A$ evaluate articles making claims about topics central to such robust disciplines as physics, biology, linguistics, and the philosophy of science.

PAISLEY LIVINGSTON McGill University

\section{Reply:}

I appreciate Paisley Livingston's comments and concerns. His main accusation, as I understand it, is that my article lacks "rigorous standards" and uses a "highly exclusionary" theoretical canon. Yes, of course, I was selective-and was bound to be-just as Livingston is selective in the authors he recommends to me, who support his own point of view. A never-ending debate. David Bohm, Ilya Prigogine, John Von Neumann, to cite a few, are "rigorous" physicists and scientists who explore the metaphoric nature and role of language and the problem of representation in science even though they themselves belong to "robust" scientific disciplines.

I do cite only one source, in Le point, for my remark on AIDS. The quotation I provide, however, is from Luc Montagnier, Nobel Prize laureate and specialist on AIDS who can hardly be accused of ignoring the complexities of the AIDS question and "hoping for a properly magic solution." Besides, please let's not turn science into a modern religion and scientists into high priests or untouchables holding the truth. That devel- 